\title{
Medusahead Dispersal and Establishment in Sagebrush Steppe Plant Communities
}

\author{
Kirk W. Davies \\ Author is Rangeland Scientist, US Department of Agriculture - Agricultural Research Service at Eastern Oregon Agricultural Research Center, \\ Burns, OR 97220, USA.
}

\begin{abstract}
Medusahead (Taeniatherum caput-medusae [L.] Nevski) is an invasive annual grass that reduces biodiversity and production of rangelands. To prevent medusahead invasion land managers need to know more about its invasion process. Specifically, they must know about 1) the timing and spatial extent of medusahead seed dispersal and 2) the establishment rates and interactions with plant communities being invaded. The timing and distance medusahead seeds dispersed from invasion fronts were measured using seed traps along $2335-\mathrm{m}$ transects. Medusahead establishment was evaluated by introducing medusahead at 1, 10,100,1 000, and 10000 seeds $\cdot \mathrm{m}^{-2}$ at 12 sites. Most medusahead seeds dispersed less than $0.5 \mathrm{~m}$ from the invasion front $(P<0.01)$ and none were captured beyond $2 \mathrm{~m}$. Medusahead seeds dispersed from the parent plants from early July to the end of October. More seeds were trapped in August than in the other months $(P<0.01)$. Medusahead establishment increased with higher seed introduction rates $(P<0.01)$. Medusahead density was negatively correlated to tall tussock perennial grass density and positively correlated to annual grass density of the preexisting plant communities $(P=0.02)$. Medusahead cover was also negatively correlated with tall tussock perennial grass density $(P=0.03)$. The results suggest that containment barriers around medusahead infestations would only have to be a few meters wide to be effective. This study also suggests that promoting or maintaining tall tussock perennial grass in areas at risk of invasion can reduce the establishment success of medusahead. Tall tussock perennial grass and annual grass density, in combination with soil data, may be useful in predicting susceptibility to medusahead invasion.
\end{abstract}

\section{Resumen}

"Medusahead" (Taeniatherum caput-medusae [L.] Nevski) es un zacate anual invasor que reduce la biodiversidad y productividad del pastizal. Para prevenir la invasión de esta especie, los manejadores del pastizal deben saber más acerca de su proceso de invasión, específicamente: 1) la época y distancia de dispersión de la semilla del "Medusahead" y 2) las tasas de establecimiento y las interacciones con las comunidades vegetales que esta invadiendo. La época y la distancia a partir de los frentes de invasión, a la que las semillas de "Medusahead" son dispersadas se midieron usando trampas a lo largo de 23 transectos de $35 \mathrm{~m}$. El establecimiento de "Medusahead" se evaluó introduciendo 1, 10, 100, 1000, y 10000 semillas · $\mathrm{m}^{-2}$ en 12 sitios. La mayoría de las semillas de "Medusahead" se dispersaron a menos de $0.5 \mathrm{~m}$ del frente de invasión $(P<0.01)$ y ninguna fue capturada más allá de $2 \mathrm{~m}$. Las semillas de "Medusahead" fueron dispersadas de las plantas madre de inicios de julio a fines de octubre, se capturaron más semillas en agosto que en los otros meses $(P<0.01)$. El establecimiento de "Medusahead" se incrementó al aumentar el número de semillas introducidas $(P<0.01)$. La densidad de "Medusahead" se correlacionó negativamente con la densidad de zacates amacollados perennes y positivamente con la densidad de zacates anuales de las comunidades vegetales preexistentes $(P=0.02)$. La cobertura de "Medusahead" también se correlacionó negativamente con la densidad de los zacates amacollados altos perennes $(P=0.03)$. Estos resultados sugieren que las barreras de contención alrededor de las infestaciones de "Medusahead" solo deberían ser de unos pocos metros de ancho para ser efectivas. Este estudio también sugiere que promover o mantener zacates amacollados altos perennes en áreas con riesgo de invasión puede reducir el éxito de establecimiento del "Medusahead". La densidad de zacates amacollados altos perennes y zacates anuales, en combinación con datos de suelo, pueden ser útiles para predecir la susceptibilidad a la invasión de "Medusahead".

Key Words: annual grass, containment, invasive plants, invasive plant management, prevention, Taeniatherum caput-medusae, weeds

\section{INTRODUCTION}

Medusahead (Taeniatherum caput-medusae [L.] Nevski) is an exotic annual grass invading rangelands in the western United

The Eastern Oregon Agricultural Research Center is jointly funded by the US Department of Agriculture - Agricultural Research Service and Oregon State University Agricultural Experiment Station.

Mention of a proprietary does not constitute a guarantee or warranty of the product by USDA, Oregon State University, or the author and does not imply its approval to the exclusion of other products.

Correspondence: Kirk W. Davies, USDA - Agricultural Research Service, Eastern Oregon Agricultural Research Center, 67826-A Hwy 205, Burns, OR 97720, USA. Email: kirk.davies@ oregonstate.edu

Manuscript received 3 May 2007; manuscript accepted 6 October 2007.
States (Young 1992). Its rapid spread into previously uninfested areas is a serious management concern (Dalh and Tisdale 1975; Monaco et al. 2005) because medusahead invasion has reduced the grazing capacity of rangelands by as much as $80 \%$ (Hironaka 1961). Medusahead litter also has a slow decomposition rate allowing it to build up over time and suppress native plants (Bovey et al. 1961). The buildup of medusahead litter also increases the amount and continuity of fine fuel, thus increasing fire frequency to the detriment of native vegetation (Torell et al. 1961; Young 1992). The result is often a loss of native species and dense monocultures of medusahead (George 1992).

Efforts to reestablish native vegetation into medusaheadinfested Intermountain rangelands have proven to be highly 
unsuccessful and expensive. Young (1992) reviewed previous research on the ecology and management of medusahead in the Great Basin and reported no inexpensive or successful options for reestablishment of native vegetation in infested rangelands. Most subsequent research has focused on medusahead control treatments where study duration has been insufficient to determine whether there have been lasting positive effects on reestablishment of native plant species (Young 2004; Monaco et al. 2005). Preventing plant invasions would be more costeffective and successful than trying to control exotic plant infestations (Zavaleta 2000; Peterson and Vieglais 2001; Simberloff 2003), thus proactive medusahead management strategies need to be developed and evaluated (Torell et al. 1961).

Successful prevention of medusahead invasions requires a better understanding of its dispersal mechanisms. Furbush (1953) and Monaco et al. (2005) suggested that the awns and small barbs on the seeds facilitate medusahead seed dispersal by adhesion. Furbush (1953) and Davies and Sheley (2007b) reported that medusahead seeds can be dispersed relatively short distances by wind. Analyzing medusahead dispersal potential with Davies and Sheley's (2007a) conceptual framework suggests that preventing animal and vehicle traffic through infestations would reduce its spread. Information detailing how far and when medusahead seeds disperse is needed to develop strategies for preventing medusahead invasions. Successful prevention also requires a better understanding of medusahead establishment rates and how establishment varies with differences in the plant community being invaded.

Information describing the establishment of medusahead is lacking. Dahl and Tisdale (1975) speculated that perennial vegetation reduces the ability of medusahead to invade because sites occupied by medusahead had previously been largely dominated by annuals. However, their study was based only on observations and thus, did not test medusahead ability to invaded sites with different compositions of perennial and annual vegetation. Furthermore, invasion may be limited by abiotic or biotic mechanisms (D'Antonio et al. 2001). If biotic factors are limiting invasion, increased propagule pressure from the invader should increase establishment; however, if biotic resistance is weak, even small number of propagules may result in successful invasion (D'Antonio et al. 2001). Understanding the relationship between plant community characteristics and medusahead invasion will provide the building blocks for developing plant communities that are resistant to medusahead invasion.

The purposes of this study were to determine timing and spatial extent of medusahead seed dispersal from established infestations in the absence of large animal, vehicle, and human vectors and to investigate medusahead establishment rates and how they vary among different plant communities. I hypothesized that 1) medusahead seeds disperse relatively short distances $(<5 \mathrm{~m})$ from the infestation; 2$)$ medusahead dispersal is correlated to slope, aspect, and medusahead infestation density; 3) increasing seed introduction rates will increase medusahead establishment; and 4) medusahead establishment is positively correlated with cover and density of annual vegetation and negatively correlated to cover and density of perennial vegetation in the preexisting plant community.

\section{METHODS}

\section{Study Area}

The study was conducted in the northwest foothills of Steens Mountain in southeastern Oregon about $65 \mathrm{~km}$ southeast of Burns, OR. Elevations at the study sites are between 1300 and $1550 \mathrm{~m}$ above sea level. Topography is variable with different slopes and aspects. Soils are a complex of different series with $20 \%$ to $35 \%$ clay content and moderate to high shrink-swell potential (Natural Resource Conservation Service 2007). Longterm average annual precipitation at study sites is between 250 and $300 \mathrm{~mm}$ (Oregon Climate Service 2007). Regional precipitation was $115 \%$ of the long-term historic record in the 2005-2006 crop year (1 October-30 September; Oregon Climate Service 2007). The study sites are sagebrush (Artemisia)-bunchgrass steppe with medusahead patch infestations. Wyoming big sagebrush (Artemisia tridentata subsp. wyomingensis [Beetle \& A. Young] S.L. Welsh) is the dominant shrub and bluebunch wheatgrass (Pseudoroegneria spicata [Pursh] A. Löve) or squirreltail (Elymus elymoides [Raf.] Swezey) is the dominant tall tussock perennial grass depending on site. Livestock and vehicles were excluded from the study sites during the experiment. Human traffic, excluding the research staff, was minimal and no large wildlife species or their tracks or feces were observed in the study sites during the experiment.

\section{Experimental Design and Measurements}

Dispersal. Medusahead dispersal was measured with $18 \times 28 \mathrm{~cm}$ sticky seed traps constructed from poster board brushed with Tree Tanglefoot Pest Barrier ${ }^{\circledR}$ (The Tanglefoot Company, Grand Rapids, MI). Sticky traps were placed along 23 transects at 0-, 0.5-, 1-, 2-, 3-, 4-, 5-, 10-, 15-, 20-, 25-, 30-, and $35-\mathrm{m}$ distances from the medusahead invasion front. Each transect was located perpendicular to randomly selected invasion fronts. Traps were placed flush with the ground by scraping vegetation from beneath trap locations. Traps were secured to the ground with four 4-inch nails inserted through 1inch washers. Seeds captured on the traps were counted and removed every week. Traps were replaced every $2 \mathrm{wk}$, or any time that they became nonadhesive across the $18 \times 28 \mathrm{~cm}$ surface. Sticky-trap transects were established on 1 June 2006 and maintained until 30 November 2006.

Slope and aspect were recorded at the point where each seedtrap transect intersected the invasion front. Percent slope was measured with a clinometer and aspect was measured with a compass and recorded as follows: North $=315^{\circ}-45^{\circ}$, East $=45^{\circ}-135^{\circ}$, South $=134^{\circ}-225^{\circ}$, and West $=225^{\circ}-315^{\circ}$. Medusahead density was measured using $10 \quad 0.2-\mathrm{m}^{2}$ frames every $0.5 \mathrm{~m}$ on transects placed perpendicular to, and centered upon, the seed-trap transects.

Establishment. Medusahead establishment was evaluated by broadcast seeding medusahead at 1, 10, 100,1000, and 10000 seeds $\cdot \mathrm{m}^{-2}$ on 15 November 2005. Seeding rates were randomly assigned to five $1-\mathrm{m}^{2}$ plots at 12 sites. Herbaceous cover and density by species were measured in each plot in late June. The five $1-\mathrm{m}^{2}$ plots at each site were combined to evaluate the influence of preexisting vegetation on medusahead density and cover. Sagebrush cover and density were measured 
at each site by centering five $50-\mathrm{m}$ transects spaced $20 \mathrm{~m}$ apart over the areas seeded with medusahead. Sagebrush canopy cover was measured by line intercept (Canfield 1941) and density was measured by counting individuals rooted inside five $2 \times 50 \mathrm{~m}$ belt transects.

\section{Statistical Analysis}

One-way analysis of variance was used to test for differences in medusahead dispersal as a function of month and treatment, and to test for cover and density differences as a function of introduction rate (S-Plus 2005). The Tukey-Kramer method was used for family-wise comparisons of treatment effects. Differences between means were considered significant if $P$ values were $\leq 0.05$. Means are reported with standard errors (mean \pm SE). Stepwise multiple linear regression was used to assess effects of slope, aspect, and medusahead-infestation density on the timing, quantity, and distance of medusahead seed dispersal (S-Plus 2005). Factors that were not significant contributors (as determined from using stepwise selection at $\alpha=0.05$ ) were removed from the analyses.

Stepwise multiple linear regression was used to select models correlating medusahead cover and density with preexisting community vegetation characteristics (S-Plus 2005). Vegetation factors that were not significant contributors (as determined from using stepwise selection at $\alpha=0.05$ ) were excluded from the final model. For these analyses, herbaceous cover and density were grouped into five functional groups to combine species expected to respond similarly to environmental perturbation, and to simplify data analysis (Boyd and Bidwell 2002): Sandberg bluegrass (Poa secunda J. Presl), tall tussock perennial grasses (mainly composed of bluebunch and squirreltail), annual grasses (almost solely comprised of cheatgrass [Bromus tectorum L.]), perennial forbs, and annual forbs. Sandberg bluegrass was treated as a separate perennial grass functional group because of its smaller stature and relatively rapid phenological development. Plants are frequently classified into functional groups based on physiological and morphological characteristics (Lauenroth et al. 1978). Plant functional groups are an important and useful classification for management (Davies et al. 2007b) and also facilitate comparisons among sites with varying species composition (Boyd and Bidwell 2002).

\section{RESULTS}

\section{Dispersal}

Medusahead seeds dispersed relatively short distances and dispersal decreased as distance increased $(P<0.01)$. The greatest number of medusahead seeds $\left(449 \pm 90\right.$ seed $\left.\cdot \mathrm{m}^{-2}\right)$ dispersed right next to the invasion front $(P<0.01)$. From 0.5 to $2 \mathrm{~m}$ from the invasion front, medusahead seed dispersal decreased from $148 \pm 42$ seed $\cdot \mathrm{m}^{-2}$ to $11 \pm 6.3$ seed $\cdot \mathrm{m}^{-2}$, respectively. Only five of the 23 transects captured medusahead seeds at $2 \mathrm{~m}$ from the invasion front and thus the quantity of seeds trapped at $2 \mathrm{~m}$ did not differ with distances $>2 \mathrm{~m}$ from the invasion front, where no seeds were trapped $(P>0.05)$. Dispersal of medusahead seeds started in July $(2.3 \pm 0.6$ seed $\cdot$ transect $\left.^{-1}\right)$ and continued through October $(2.3 \pm 0.8$ seed $\cdot$ transect $\left.^{-1}\right)$. The number of medusahead seeds trapped

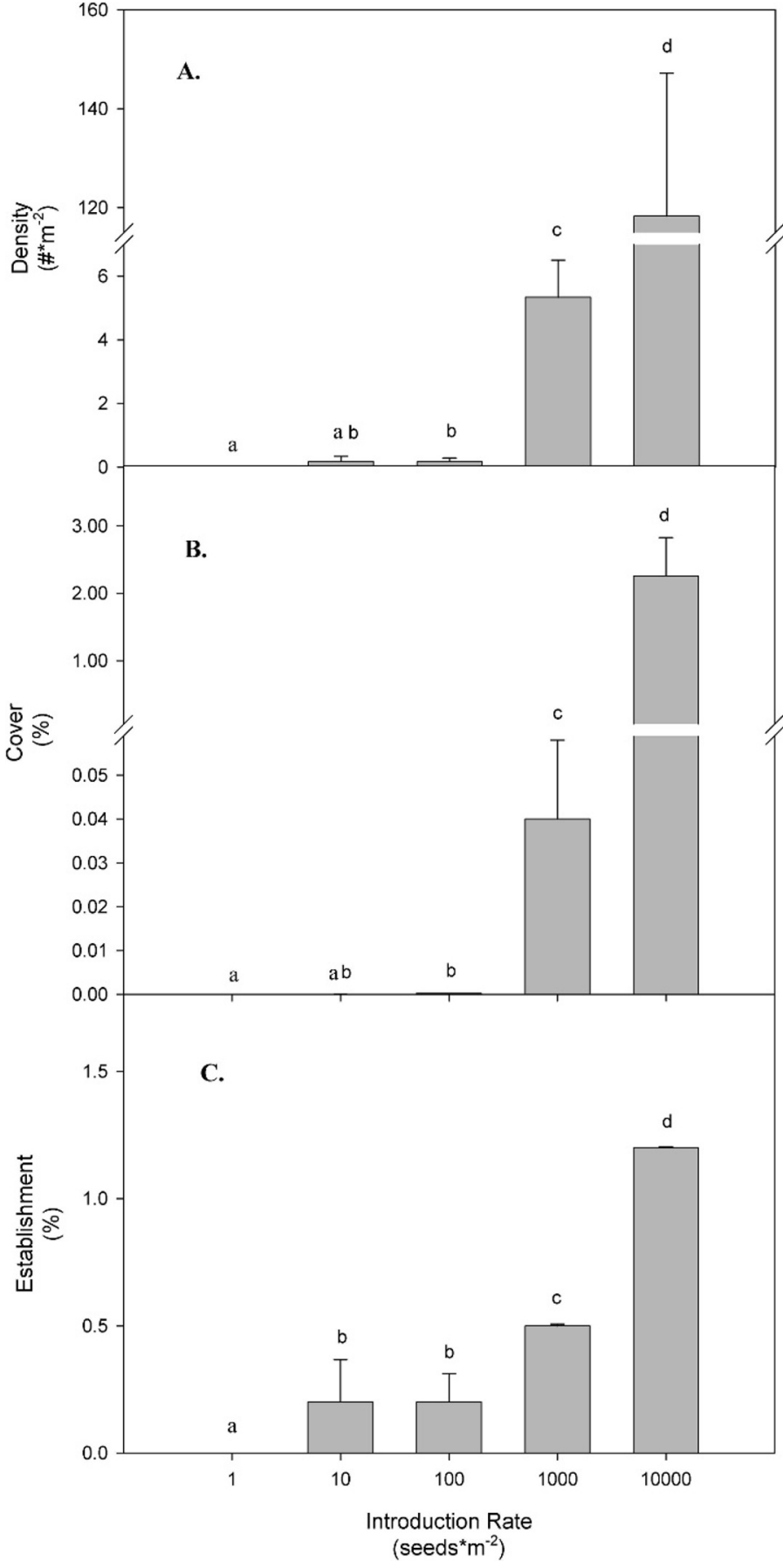

Figure 1. A, Medusahead density; B, cover; and C, percent establishment (mean $+\mathrm{SE})$ at different medusahead introduction rates. Different lowercase letters indicate differences among rates $(P<0.05)$.

varied by month $(P<0.01)$ with the greatest number of seeds trapped in August $\left(20 \pm 4.9\right.$ seed $\cdot$ transect $\left.^{-1} ; P<0.01\right)$. Slope, aspect, and medusahead infestation density were not correlated with the distance, quantity, or timing of medusahead seeds dispersal $(P>0.05)$.

\section{Establishment}

Medusahead density and cover varied by seed introduction rate $(P<0.01$; Figs. 1A and 1B). Medusahead density and cover were greatest at the highest seed introduction rate $(P<0.01)$. 


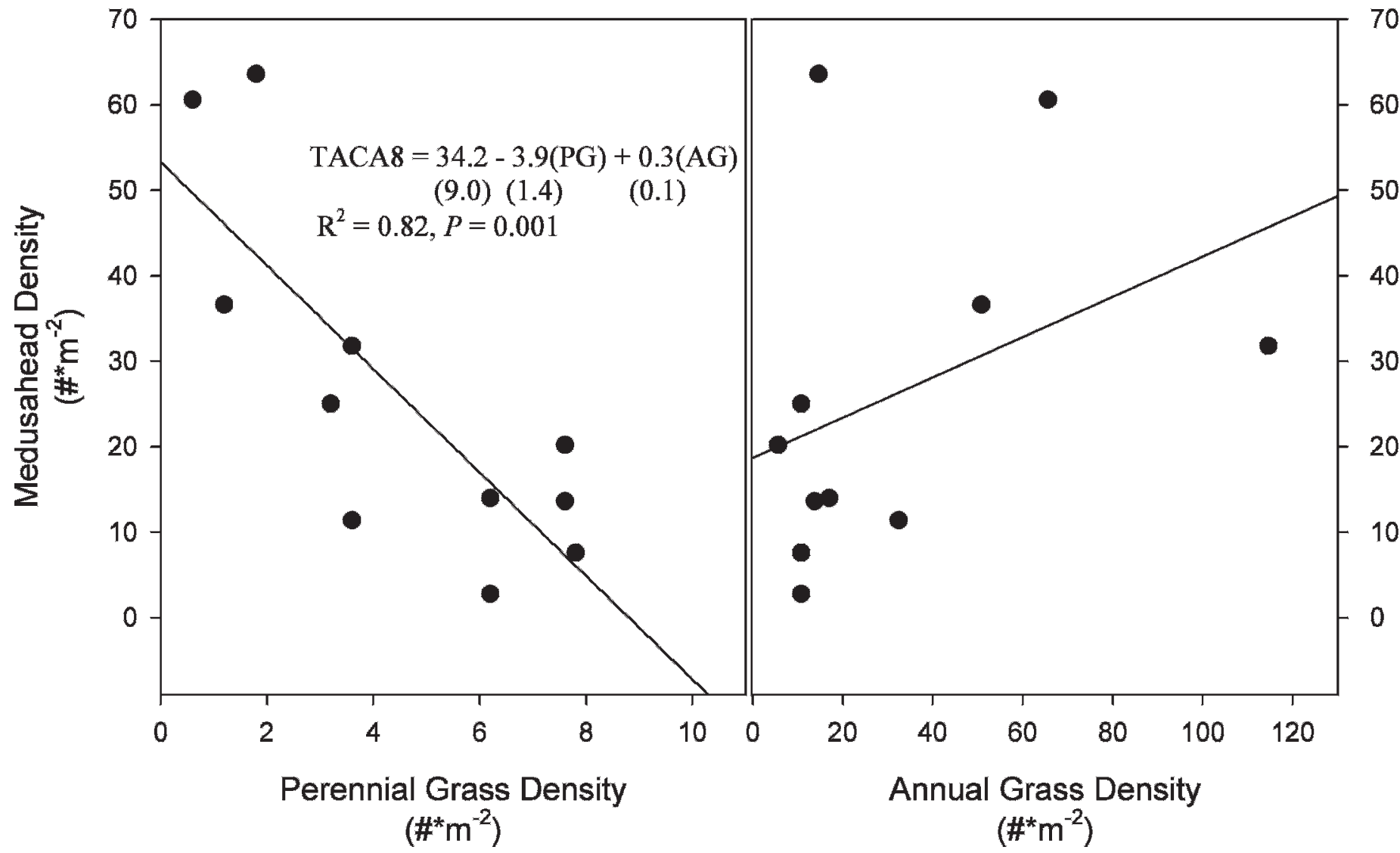

Figure 2. Scatter plot of medusahead density across tall tussock perennial grass and annual grass densities of the preexisting plant community with regression lines. TACA8 indicates medusahead; PG, tall tussock perennial grass; and AG, annual grass.

The second highest seed introduction rate had greater medusahead density and cover than lower seed introduction rates $(P<0.01)$; however, medusahead density and cover did not differ between the 10 and 100 seeds $\cdot \mathrm{m}^{-2}$ seed introduction rates $(P>0.05)$. No medusahead established when introduced at the 1 -seed $\cdot \mathrm{m}^{-2}$ rate and cover and density of medusahead was low for seeding rates of 10 and 100 seeds $\cdot \mathrm{m}^{-2}$. The percent of medusahead seeds that established varied with seed introduction rate $(P<0.01$; Fig. $1 C)$. Percentage of medusahead establishment increased with increasing seed introduction rates $(P<0.05)$, except when the rate was increased from 10 to 100 seeds $\cdot \mathrm{m}^{-2}(P>0.05)$.

Medusahead density was negatively correlated to tall tussock perennial grass density and positively correlated to annual grass density ( $P=0.02$; Fig. 2$)$. These correlations explain $82 \%$ of the variation in medusahead density $\left(R^{2}=0.82, P<0.01\right)$. Medusahead density was not correlated to density or cover of Sandberg bluegrass and forb functional groups, or to bare ground and litter values $(P>0.05)$. Tall tussock perennial grass density was also negatively correlated to medusahead cover and explained $44 \%$ of its variation $\left(R^{2}=0.44, P=0.03\right)$. No other explanatory variables were correlated with medusahead cover $(P>0.05)$.

\section{DISCUSSION}

This investigation of the establishment and dispersal of medusahead provides information needed to develop medusa- head prevention plans and parameterize invasion models. Understanding the dispersal of an invasive species is critical to limiting its spatial expansion (Davies and Sheley 2007a). Information describing the relationships between medusahead establishment and characteristics of the preexisting plant community is vital to predicting susceptibility to invasion and developing plant communities that are resistant to medusahead invasion.

Medusahead seeds are well adapted for dispersal by adhesion to moving objects (Monaco et al. 2005). In the absence of vehicle and large animal traffic, medusahead seeds disperse relatively short distances. This suggests that narrow $(\sim 3 \mathrm{~m})$ containment zones around medusahead infestations would successfully suppress invasion into surrounding plant communities.

The relatively long period of medusahead seed dispersal from July to October may be an adaptation to increase the likelihood of adhesion to animals. This long period of disarticulation has not been previously reported and has significant impacts to management of plant communities with patch invasions of medusahead. Livestock, humans, and vehicles should probably be prevented from traversing medusahead infestations during the months medusahead seeds disarticulate to limit dispersal of medusahead seeds.

The lack of correlation between slope, aspect, and medusahead infestation density with dispersal may preclude development of accurate predictive models of local medusahead dispersal based on environmental-site or vegetation character- 
istics. However, because medusahead disperses relatively short distances in the absence of large animal and vehicle vectors, these models may not be necessary for successful prevention of medusahead dispersal.

Establishment rate of medusahead increased with seeding rate suggesting that as the medusahead invasion progresses (i.e., more individuals and seeds per unit area) the percentage of seeds establishing increases. Launchbaugh and Owensby (1969) and Casler et al. (1999) reported that increased seeding rates of desirable plant species decreased the percentage of establishment. The apparent contradiction could be the result of functional dissimilarities between desirable plant species and invaders, such as earlier phenology of medusahead, or site differences. Booth et al. (2003) reported that in the Great Basin, cheatgrass depleted resources differently than native species. The increasing establishment rate of medusahead with increased propagule pressure (introduction rate) suggests that biotic factors are limiting invasion. Invasive plant propagule pressure should have a strong effect on invader establishment when biotic resistance is strong (D'Antonio et al. 2001). The negative correlation of medusahead cover and density with tall tussock perennial grass density also supports the hypothesis that these communities' resistance to invasion is biotic.

This study supports the conclusions of Dahl and Tisdale (1975), who speculated that tall tussock perennial grass was the best barrier to medusahead invasion. Tall tussock perennial grasses dominate the understory and produce more cover and biomass than the other herbaceous functional groups in late seral Wyoming big sagebrush plant communities (Davies et al. 2006, 2007a). This suggests maintaining tall tussock perennial grass is critical to preventing medusahead invasion and increasing tall tussock perennial grass density would reduce the susceptibility of a site to medusahead invasion. The positive correlation between medusahead density and annual grass density of the preexisting plant community also supports the conclusion of Dahl and Tisdale (1975) that medusahead appears to invade areas previously dominated by annuals. The lack of correlation between Sandberg bluegrass and medusahead suggests that Sandberg bluegrass does not compete very effectively with medusahead. Young (1992) observed that medusahead-infested areas of the Great Basin were devoid of Sandberg bluegrass, even in areas where it previously was the most frequent perennial grass species.

Understanding the establishment and dispersal of medusahead improves the ability of land managers to prevent medusahead invasions. Preventing medusahead invasion will probably be more cost-effective and successful than trying to control it after establishment. Prevention is a critical component to developing a successful invasive plant management program (Sheley et al. 1996; DiTomaso 2000).

\section{MANAGEMENT IMPLICATIONS}

Livestock should probably be removed from medusaheadinfested sagebrush steppe rangelands during the period of seed disarticulation to reduce the dispersal of medusahead seeds. Vehicles are also probably dispersal vectors for medusahead and thus, decreasing their contact with medusahead when seeds could be dispersed would probably increase prevention success.
Site differences and interannual variability in precipitation can be expected to influence medusahead seed development and disarticulation and thus, when livestock and vehicles should be excluded from infestations may vary from year to year and site to site. Containment zones around infestations can probably be relatively narrow; however, correctly identifying the edge of the infestation is critical. Many medusahead infestations have a diffuse boundary that requires careful scrutiny to identify. Systematic searching for and eradication of new satellite populations will still be necessary to successfully contain medusahead infestations. More research is needed to quantify the dispersal of medusahead by vehicles and animals, especially when soils are adhesive due to moisture accumulation and could disperse medusahead seeds when they adhere to vectors. Tall tussock perennial grasses appear to be a critical component of sagebrush rangelands that are resistant to medusahead invasion. Promoting and maintaining tall tussock perennial grass should be a management priority on rangelands susceptible to medusahead invasion. Perennial grass and annual grass density may be useful indicators of site susceptibility to medusahead invasion.

\section{ACKNOWLEDGMENTS}

The author thanks Stacy McKnight, Rachel Svejcar, and Brett Bingham for the assistance with data collection. Roger Sheley's review of the initial study design was appreciated. Thoughtful reviews of this manuscript by Dustin Johnson, Edward Vasquez, and anonymous reviewers were appreciated. The author also thanks the private landowners and the Burns District of the Bureau of Land Management for providing the land for this research project.

\section{LITERATURE CITED}

Booth, M. S., M. M. Caldwell, and J. M. Stark. 2003. Overlapping resource use in three Great Basin species: implications for community invasibility and vegetation dynamics. Journal of Ecology 91:36-48.

Bovey, R. W., D. Le Tourneau, and L. C. Erickson. 1961. The chemical composition of medusahead and downy brome. Weeds 9:307-311.

Boyd, C. S., AND T. G. BIDWELL. 2002. Effects of prescribed fire on shinnery oak plant communities in western Oklahoma. Restoration Ecology 10:324-333.

Canfield, R. H. 1941. Application of the line interception methods in sampling range vegetation. Journal of Forestry 39:388-394.

Casler, M. D., D. C. West, and D. J. Undersander. 1999. Establishment of temperate pasture species into alfalfa by frost-seeding. Agronomy Journal 91:916-921.

D’Antonio, C., J. Levine, and M. Thomsen. 2001. Ecosystem resistance to invasion and the role of propagule supply: a California perspective. Journal of Mediterranean Ecology 2:233-245.

DAHL, B. E., AND E. W. TISDALE. 1975. Environmental factors relating to medusahead distribution. Journal of Range Management 28:463-468.

Davies, K. W., J. D. Bates, and R. F. Miller. 2006. Vegetation characteristics across part of the Wyoming big sagebrush alliance. Rangeland Ecology and Management 59:567-575.

Davies, K. W., J. D. Bates, and R. F. Miller. 2007a. Short-term effects of burning Wyoming big sagebrush steppe in southeast Oregon. Rangeland Ecology and Management 60:515-522.

Davies, K. W., M. L. Pokorny, R. L. Sheley, and J. J. James. 2007b. Influence of plant functional group removal on soil inorganic nitrogen concentrations in native grasslands. Rangeland Ecology and Management 60:304-310.

Davies, K. W., And R. L. Sheley. 2007a. A conceptual framework for preventing the spatial dispersal of invasive plants. Weed Science 55:178-185. 
Davies, K. W., and R. L. Sheley. 2007b. Influence of neighboring vegetation height on seed dispersal: implications for invasive plant management. Weed Science (in press).

DiTomaso, J. M. 2000. Invasive weeds in rangelands: species, impacts, and management. Weed Science 48:255-265.

Furbush, P. 1953. Control of medusa-head on California ranges. Journal of Forestry 51:118-121.

GeorGe, M. R. 1992. Ecology and management of medusahead. University of California Range Science Report 23:1-3.

Hironaka, M. 1961. The relative rate of root development of cheatgrass and medusahead. Journal of Range Management 14:263-267.

Lauenroth, W. K., J. L. Dodd, and P. L. Sims. 1978. The effects of water- and nitrogen-induced stresses on plant community structure in a semiarid grassland. Oecologia 36:211-222.

Launchbaugh, J. L., and C. E. Owensby. 1969. Seeding rate and first-year stand relationships for six native grasses. Journal of Range Management 22: 414-417.

Monaco, T. A., T. M. Osmond, and S. A. Dewey. 2005. Medusahead control with falland spring-applied herbicides in northern Utah foothills. Weed Technology 19:653-658.

Natural Resource Conservation Service. 2007. Soil survey. Available at: http:// soils.usda.gov/survey/. Accessed 26 February 2007.
Oregon Climate Service. 2007. Oregon Climate Service. Available at: http:// www.ocs.oregonstate.edu/index.html. Accessed 27 February 2007.

Peterson, A. T., and D. A. Vieglais. 2001. Predicting species invasions using ecological niche modeling: new approaches from bioinformatics attack a pressing problem. BioScience 51:363-371.

S-PLus [computer program]. 2005. Version 7.0. Seattle, WA, USA: Mathsoft, Inc.

Sheley, R. L., T. J. SvejCaR, And B. D. Maxwell. 1996. A theoretical framework for developing successional weed management strategies on rangeland. Weed Technology 10:766-773.

SimberLofF, D. 2003. Eradication-preventing invasions at the outset. Weed Science 51:247-253.

Torell, P. J., L. C. ERICKson, and R. H. HaAs. 1961. The medusahead problem in Idaho. Weeds 9:124-131.

Young, J. A. 1992. Ecology and management of medusahead (Taeniatherum caput-medusae ssp. asperum [SIMK.] Melderis). Great Basin Naturalist 52:245-252.

Young, S. L. 2004. Natural product herbicides for control of annual vegetation along roadsides. Weed Technology 18:580-587.

Zavaleta, E. 2000. Valuing ecosystem services lost to Tamarix invasion in the United States. In: H. A. Mooney and R. J. Hobbs [EDs.]. Invasive species in a changing world. Washington, DC, USA: Island Press. p. 261300. 